Revista Brasileira de Farmacognosia Brazilian Journal of Pharmacognosy 22(6): 1276-1281, Nov./Dec. 2012

Article

Received 8 May 2012

Accepted 22 Aug 2012

Available online 18 Sep 2012

Keywords:

beauvericin

citotoxic activity

endophytic fungus

Fusarium oxysporum

Leishmania braziliensis

ISSN 0102-695X

http://dx.doi.org/10.1590/S0102-

695X2012005000106

\section{Bioactive extracts and chemical constituents of two endophytic strains of Fusarium oxysporum}

\author{
Andréa M. do Nascimento, ${ }^{1}$ Raphael Conti, ${ }^{2}$ Izabel C. C. Turatti, ${ }^{3}$ \\ Bruno C. Cavalcanti, ${ }^{4}$ Letícia V. Costa-Lotufo, ${ }^{4}$ Cláudia Pessoa, ${ }^{4}$ \\ Manoel O. de Moraes, ${ }^{4}$ Viviane Manfrim, ${ }^{2}$ Juliano S. Toledo, ${ }^{5}$ \\ Angela K. Cruz, ${ }^{5}$ Mônica T. Pupo ${ }^{*}$
}

\author{
${ }^{I}$ Departamento de Química, Instituto de Ciências Exatas e Biológicas, Universidade \\ Federal de Ouro Preto, Brazil, \\ ${ }^{2}$ Departamento de Ciências Farmacêuticas, Faculdade de Ciências Farmacêuticas \\ de Ribeirão Preto, Universidade de São Paulo, Brazil, \\ ${ }^{3}$ Departamento de Física e Química, Faculdade de Ciências Farmacêuticas de \\ Ribeirão Preto, Universidade de São Paulo, Brazil, \\ ${ }^{4}$ Departamento de Fisiologia e Farmacologia, Faculdade de Medicina, Universidade \\ Federal do Ceará, Brazil, \\ ${ }^{5}$ Departamento de Biologia Celular e Molecular, Faculdade de Medicina de Ribeirão \\ Preto, Universidade de São Paulo, Brazil.
}

\begin{abstract}
Ethyl acetate extracts of cultures grown in liquid Czapek and on solid rice media of the fungal endophyte Fusarium oxysporum SS46 isolated from the medicinal plant Smallanthus sonchifolius (Poepp.) H. Rob., Asteraceae, exhibited considerable cytotoxic activity when tested in vitro against human cancer cells. Chromatographic separation yielded anhydrofusarubin (1) and beauvericin (2) that were identified based on their ${ }^{1} \mathrm{H}$ and ${ }^{13} \mathrm{C}$ NMR data. Compounds $\mathbf{1}$ and $\mathbf{2}$ showed the strongest cytotoxic activity against different cancer cell lines. Compound $\mathbf{2}$ also showed promising activity against Leishmania braziliensis. Hexanic extract of $F$. oxysporum SS50 grown on solid rice media also afforded a mixture of compounds that displayed cytotoxic activity against different cancer cell lines. Chemical analysis of the mixture of compounds, investigated by gas chromatography-mass spectrometry (GC-MS), showed that there was a predominance of methyl esters of fatty acids and alkanes.
\end{abstract}

\section{Introduction}

Microorganisms are recognized as prolific producers of bioactive natural products, many of them useful as clinical drugs (Gunatilaka, 2006; Newman \& Cragg, 2012). Newman and Gragg (2012) recently emphasized that efforts to discover new bioactive natural products should focus on microorganisms living in interactions with their hosts. Endophytes are one type of such microorganisms, since they spend the whole or part of their lifespan inside the healthy tissues of the host inter- and/or intracellularly without causing discernible symptoms of plant disease (Borges et al., 2009). Natural products from fungal endophytes have a broad spectrum of biological activities, such as antimicrobial, immunosuppressant, anticancer, and also may act as biocontrol agents (Gunatilaka, 2006; Borges et al., 2009).

As part of our ongoing research on endophytic fungi found in association with Asteraceae species we have identified several bioactive extracts and compounds, as well as novel natural products (Gallo et al.; 2009; 2010; Guimarães et al., 2010; Borges et al., 2011).

In this paper, we report the chemical and biological of two fungal strains of Fusarium oxysporum, coded as SS46 and SS50, isolated as endophytes from the medicinal plant Smallanthus sonchifolius (Asteraceae).

\section{Materials and Methods}

General procedures

1D (regular ${ }^{1} \mathrm{H}$ and ${ }^{13} \mathrm{C}$ ) and $2 \mathrm{D}$ nuclear magnetic resonance (NMR) spectra were recorded in $\mathrm{CDCl}_{3}$ on Bruker spectrometer (DPX-500), working at $500 \mathrm{MHz}$ for ${ }^{1} \mathrm{H}$, and at $125 \mathrm{MHz}$ for ${ }^{13} \mathrm{C}$. Tetramethylsilane (TMS) was used as internal reference. Column chromatographies were performed over silica gel 60, 230-280 mesh 
(Ultra Chem) or Sephadex LH-20. Vacuum liquid chromatography (VLC) was carried out silica gel 60 H, 70-230 mesh (Merck). Thin-Layer chromatography (TLC) was performed on sílica gel $60 \mathrm{GF}_{254}$ (Merck). Spots were located by spraying with anisaldehydesulfuric acid reagent, heated at $110^{\circ} \mathrm{C}$.

\section{Isolation of strains}

The endophytic fungal strains were isolated from the roots of $S$. sonchifolius according to the procedure described by Gallo et al. (2009). After collection, the plant material was washed with water and surface sterilized by immersion in $70 \%$ aqueous ethanol $(2.5 \mathrm{~min})$, followed by $2.5 \%$ aqueous sodium hypochlorite (30", 60 " or 90 "), and finally with $70 \%$ aqueous ethanol $(1 \mathrm{~min})$. After these procedures, the leaves and roots were rinsed with sterilized water. This latter water was incubated in Petri dishes to ensure the elimination of all epiphytic microorganisms. Small pieces of the leaves and roots were excised and placed on agar in Petri dishes containing potato dextrose agar (PDA) medium at $30^{\circ} \mathrm{C}$. Individual hyphal tips of the emerging fungi were removed and placed on PDA slants.

\section{Fermentation and extraction procedures}

Both $F$. oxysporum strains were cultured in liquid Czapek and solid rice media. Liquid cultures were conducted in two steps. First, the silica stored fungi were inoculated onto PDA-containing medium in Petri dishes and incubated at $30{ }^{\circ} \mathrm{C}$ for seven days. After this period, the pre-inoculum was prepared by transferring the agar plugs $(0.5 \mathrm{~cm}$ diameter $)$ cut from the 7-day-old original cultures into $50 \mathrm{~mL}$ Falcon flasks containing $10 \mathrm{~mL}$ of rich medium ( $5 \mathrm{~g}$ tryptone, $10 \mathrm{~g}$ dextrose, $3 \mathrm{~g}$ yeast extract, $10 \mathrm{~g}$ malt extract, in $1000 \mathrm{~mL}$ final volume of $\mathrm{H}_{2} \mathrm{O}, \mathrm{pH} 6.2 \pm 0.2$ ), and incubated for three days at $25^{\circ} \mathrm{C}$, $120 \mathrm{rpm}$. After this period, the pre-inoculum $(20 \mathrm{~mL})$ was transferred to a $1000 \mathrm{~mL}$ Erlenmeyer flask containing $200 \mathrm{~mL}$ of Czapek medium and incubated at $25^{\circ} \mathrm{C}$ for 14 or 21 days $(120 \mathrm{rpm})$. Nine Erlenmeyer flasks were used for a large scale extract production, aiming to isolate secondary metabolites. After 21 days $200 \mathrm{~mL}$ of ethanol were added to each flask, the resulting suspension was vacuum-filtered and the filtrate fractionated by liquidliquid partition with ethyl acetate. The resulting organic layer was evaporated under reduced pressure to produce the ethyl acetate extracts (EaL). Fermentations of $F$. oxysporum SS46 and $F$. oxysporum SS50 carried out for fourteen days yielded, respectively, $1.4289 \mathrm{~g}$ (coded $\left.\mathrm{SS} 46-\mathrm{EaL}_{14}\right)$ and $1.0884 \mathrm{~g}$ (coded $\mathrm{SS} 50-\mathrm{EaL}_{14}$ ) of $\mathrm{EaL}$ extracts. After 21 days of incubation, F. oxysporum SS46 yielded $0.8082 \mathrm{~g}$ of EaL extract (coded SS46-EaL). $F$. oxysporum SS50 was cultured only for 14 days. A Falcon flask containing seed medium without inoculum was submitted to the same preculture conditions. The resulting pre-inoculum was transferred to Czapek medium and treated in the same way for control purposes.

The solid fermentation experiments were carried out in ten $500 \mathrm{~mL}$ Erlenmeyer flasks containing $90 \mathrm{~g}$ of parboiled rice in $90 \mathrm{~mL}$ distilled water per flask, previously twice autoclaved at $120^{\circ} \mathrm{C}$ for $40 \mathrm{~min}$ for each fungal strain. Agar plugs (about $2 \times 2 \mathrm{~cm}$ ) cut from the 7-day-old original cultures on PDA agar were used for inoculation. One flask, without inoculum, was kept for control use. After 21 days incubation in a BOD (Biological Oxygen Demand) device at $30{ }^{\circ} \mathrm{C}, 150 \mathrm{~mL}$ of methanol were added to each flask and the contents were allowed to stand overnight at room temperature. The methanol was filtered and evaporated under reduced pressure yielding the methanol extract, which was submitted to the liquid-liquid partition with hexane and ethyl acetate. The resulting organic layer was evaporated under reduced pressure to produce the hexanic and ethyl acetate extracts. Solid culture of F. oxysporum SS46 afforded $0.41 \mathrm{~g}$ of the hexanic extract (SS46-HxS) and $2.89 \mathrm{~g}$ of the ethyl acetate extract (SS46-EaS). Fermentation of $F$. oxysporum SS50 yielded $0.16 \mathrm{~g}$ of the hexanic extract (SS50-HxS) and $0.84 \mathrm{~g}$ and ethyl acetate extract (SS50$\mathrm{EaS})$.

\section{Isolation of compounds}

The SS46-EaS extract $(2.77$ g $)$ was chromatographed by vacuum liquid chromatography (VLC) on silica gel and eluted with hexane, hexane/ethyl acetate (gradient), ethyl acetate/methanol (gradient) and methanol to give ten fractions (F1-F10). Fraction F5 $(100 \mathrm{mg}$ ) was purified by chromatography on a Sephadex LH-20 column using methanol as eluent to give 1 (5.2 $\mathrm{mg})$. The SS46-EaL extract $(89 \mathrm{mg}$ ) was purified by chromatography on a column packed with silica gel 60 . Elution with hexane/ethyl acetate 8:2 and 2:8, (crescent gradient), ethyl acetate/methanol 19:1 and methanol $100 \%$ afforded twenty fractions, which were combined in nine sub-fractions according to TLC analysis. The sub-fraction $7(6.1 \mathrm{mg})$ was identified as 2 . The SS50HxS extract (155.4 mg), obtained after 21 days on rice medium, was investigated by gas chromatography-mass spectrometry (GC-MS).

\section{Gas chromatography-mass spectrometry (GC-MS)}

The SS50-HxS extract was analyzed on a Shimadzu QP-2010 gas chromatograph interfaced to a mass spectrometer (GC-MS). The following conditions were used: DB-5MS column (30 m x $0.25 \mathrm{~mm} \times 0.25$ $\mu \mathrm{m})$; helium $(99.999 \%)$ carrier gas at a constant flow of $1.1 \mathrm{~mL} / \mathrm{min} ; 1 \mu \mathrm{L}$ injection volume; injector split ratio of 1:40; injector temperature $240{ }^{\circ} \mathrm{C}$; electron impact 
mode at $70 \mathrm{eV}$; ion-source temperature $280^{\circ} \mathrm{C}$. The oven temperature was programmed from $100^{\circ} \mathrm{C}$ (isothermal for $5 \mathrm{~min}$ ), with an increase of $10^{\circ} \mathrm{C} / \mathrm{min}$ to $250^{\circ} \mathrm{C}$ (isothermal for $5 \mathrm{~min}$ ), and $10{ }^{\circ} \mathrm{C} / \mathrm{min}$ to $280{ }^{\circ} \mathrm{C}$ (isothermal for 15 min). A mixture of linear hydrocarbons $\left(\mathrm{C}_{9} \mathrm{H}_{20}-\mathrm{C}_{40} \mathrm{H}_{82}\right)$ was injected under the same conditions as standards, and identification of constituents performed by comparing the spectra obtained with those of the equipment's database (Wiley 7 lib), and by using the Kovats Index, calculated for each constituent as previously described (Adams, 1995; Van den Dool \& Kratz, 1963).

\section{Cytotoxic bioassay}

Human tumor cell lines MDA-MB435 (melanoma), HCT-8 (colon), and SF295 (brain) were obtained from National Cancer Institute (Bethesda, MD, USA). All cell lines were cultured in RPMI1640 medium, supplemented with $10 \%$ fetal bovine serum and $1 \%$ antibiotics (penicillin and streptomycin). Cultures were maintained in a humidified incubator at $37{ }^{\circ} \mathrm{C}$ and $5 \%$ $\mathrm{CO}_{2}$ atmosphere. The cytotoxic effect was assessed using the MTT-dye reduction assay for cell viability described by Mosmann (1983) according to an established protocol. Briefly, tumor cells were placed in 96-well plates at the following densities: $0.7 \times 10^{5}$ (HCT-8), $0.6 \times 10^{5}$ (SF295), and $0.1 \times 10^{6}(\mathrm{MDA}-\mathrm{MB} 435)$ cells $/ \mathrm{mL}$. Extracts were tested in a single concentration $(50 \mu \mathrm{g} / \mathrm{mL})$ and pure compounds in a range between 0.39 and $25 \mu \mathrm{g} / \mathrm{mL}$ during $72 \mathrm{~h}$. Control groups received the same amount of vehicle and doxorubicin (Doxolem ${ }^{\circledR}$, Zodiac Produtos Farmacêuticos S/A, Brazil), which was used as a positive control. Growth inhibition rates were quantified as the percentage of control absorbance by the reduced dye at $550 \mathrm{~nm}$ in accordance with the following equation:

Inhibition rate $=[(\mathrm{OD}$ control well $-\mathrm{OD}$ treated well) $\mathrm{x}(\mathrm{OD} \text { control well) })^{-1} \mathrm{x} 100$.

Each sample was tested in two independent experiments performed in triplicates. The results consisted of the average value for each experimental unit. The IC50 values and their 95\% confidence intervals were obtained by non linear regression using the GraphPad Prism program (Intuitive Software for Science, San Diego, CA). An activity scale was utilized to appraise the cytotoxic potential of the tested samples: inactive samples (I), samples with low activity (LA, cell growth inhibition between 1-50\%), moderated activity (MA, cell growth inhibition between 50-75\%), and high activity (HA, cell growth inhibition between 75-100\%).

\section{Leishmanicidal assay}

The L. braziliensis strain H3227 (MHOM/
BR/94/H-3227) used in this study was kindly provided by Prof. Dr. Aldina Barral (Professor of Immunology, Centro de Pesquisas Gonçalo Moniz, FIOCruz-Bahia, Brazil). The parasites were maintained in vitro in M199 medium (GIBCO, Grand Island, NY) at $26^{\circ} \mathrm{C}$ supplemented with $10 \%$ heat inactivated fetal calf serum, $2 \%$ human urine, $20 \mathrm{mM}$ HEPES, $4 \mathrm{mM} \mathrm{NaHCO}, 10 \mathrm{U} / \mathrm{mL}$ of penicillin and $100 \mu \mathrm{g} / \mathrm{mL}$ of streptomycin (GIBCO).

The anti-promastigote assay was carried out according to the method of Dutta et al. (2005). Beauvericin (2) was serially diluted from 0.02 to $10 \mu \mathrm{M}$ in Schneider's medium (supplemented with 10\% FBS and $2 \%$ human urine) containing $2 \times 10^{5}$ parasites $/ \mathrm{mL}$. A total of $4 \times 104$ parasites were seeded per well in 96-well microplates incubated at $26{ }^{\circ} \mathrm{C}$ until the end of the $\log$ phase. After, $100 \mu \mathrm{g}$ of 3-(4,5-dimethylthiazol-2-yl)-2,5diphenyl tetrazolium bromide (MTT) dissolved in $10 \mu \mathrm{L}$ of PBS was added per well, and the plates were incubated at $37^{\circ} \mathrm{C}$ for $4 \mathrm{~h}$. Following incubation, the plates were centrifuged at $3000 \times \mathrm{g}$ for $5 \mathrm{~min}$, the supernatant was removed, and precipitated formazan was dissolved in 100 $\mu \mathrm{L}$ of dimethyl sulfoxide. The absorbance was measured at $492 \mathrm{~nm}$, and the data for two independent assays performed in triplicate were analyzed by non-linear regression with variable slope (Graph Pad Prism 5.0 software). The EC50 was defined as the effective drug concentration that inhibits parasite proliferation by $50 \%$ compared with a non-treated culture. Geneticin (G418) was used as a positive control (EC50 $0.007 \mu \mathrm{M})$.

\section{Results and Discussion}

Extracts obtained after fourteen days of incubation of both endophytic fungi in liquid Czapek medium did not show any relevant cytotoxic activity. The best incubation time for production of cytotoxic compounds was 21 days, in both liquid and solid media. The most active extracts were found to be SS50-HxS and SS46-EaL, which showed high cytotoxic activities against the three cancer cell lines (Table 1). Extract SS46-EaS also showed high activity against HCT-8 cells and moderate activity against SF295 cells. Interestingly, $F$. oxysporum SS46 produced bioactive ethyl acetate extracts in both liquid and solid media. On the other hand, F. oxysporum SS50 produced bioactive compounds of lower polarity only in solid medium, as observed for the high activities of SS50-HxS extract. In our previous investigation, $F$. oxysporum SS46 had already produced high cytotoxic ethyl acetate extracts; however no cytotoxic activity had been detected for F. oxysporum SS50 (Gallo et al., 2009). This result can be explained by the different extraction methods, because in that previous screening all the fungal solid cultures extracts were partitioned only with ethyl acetate. Chemical investigation was focused on the most active extracts: SS46-EaS, SS46-EaL and SS50-HxS. 
Table 1. In vitro cytotoxic activity of the extracts obtained from the endophytes $F$. oxysporum SS46 and $F$. oxysporum SS50 after 21 days of fermentation $(50 \mu \mathrm{g} / \mathrm{mL})$.

\begin{tabular}{lccc}
\hline \multirow{2}{*}{ Crude extract* } & \multicolumn{3}{c}{ Inhibition of cell growth (\%) } \\
\cline { 2 - 4 } & HCT-8 & MDA-MB435 & SF295 \\
\hline SS46-HxS & 55.83 & 16.53 & 43.61 \\
SS50-HxS & 97.72 & 90.53 & 83.78 \\
Solid medium control Hx- & 35.41 & $\mathrm{I}$ & $\mathrm{I}$ \\
extract** & & & \\
SS46-EaS & 84.82 & 36.23 & 67.02 \\
SS50-EaS & 43.45 & $\mathrm{I}$ & 0.77 \\
Solid medium control Ea- & 31.53 & 5.74 & $\mathrm{I}$ \\
extract** & & & \\
SS46-EaL & 100.00 & 99.32 & 100.00 \\
Liquid medium control extract & $\mathrm{I}$ & $\mathrm{I}$ & $\mathrm{I}$ \\
Doxorubicin & 97.30 & 98.27 & 96.94 \\
\hline
\end{tabular}

* SS: fungal strain; Hx: hexane; Ea: ethyl acetate; S: solid rice medium; L: liquid Czapek medium for 21 days; **Extract from culture media without fungus; HCT-8: colon cancer cells; MDA-MB435: melanoma cells; SF295: brain cancer cells; high activiy: $>75 \%$; moderated activity: 50 to $75 \%$; low activity: $<50 \%$; I: inactive.

The SS50-HxS extract was analyzed by GC-MS. Twenty-seven components were detected in this extract, and twelve of them $(76.8 \%)$ were identified by the GCMS data (Table 2). According to our results, there is a predominance of alkanes and fatty acid methyl esters in this extract and the main constituents are: $(9 \mathrm{Z}, 12 \mathrm{Z})$ octadecadienoic acid methyl ester (54.45\%), methyl hexadecanoate $(9.73 \%)$ and $(9 Z)$-octadecenoic acid methyl ester $(4.70 \%)$. Fifteen compounds remained unidentified because the spectral data could not be associated with any compound database system (Wiley lib 7). The analysis of hexane rice-control extract (without fungus), showed that there is little correlation in their chemical composition. There are only five compounds in common in the extracts: 1,2-benzenedicarboxylic acid, bis(2-methylpropyl) ester, methyl hexadecanoate, (9Z)-octadecenoic acid methyl ester, clionasterol and stigmast-4-en-3-one. Therefore, seven compounds differentiate the SS50-HxS extract from the culture medium control extract: $(2 E, 4 E)$ decadienal, pentadecane, hexadecane, heptadecane octadecane, $(9 Z, 12 Z)$-octadecadienoic acid methyl ester and dehydroergosterol. All extracts analyzed in this study differed considerably in their secondary metabolites. The SS50-HxS showed pronounced cytotoxicity against the three human cancer cell lines. As the major components of the hexane extract are a mixture of three methyl esters (methyl hexadecanoate, (9Z)-octadecenoic acid methyl ester and $(9 Z, 12 Z)$-octadecadienoic acid methyl ester), which represents $68.88 \%$ of the extract, presumably they should be responsible for the high cytotoxic activity of the crude extract. The culture medium control extract did not show cytotoxic activity (Table 1). This extract also contains a fatty acid methyl esters mixture, but a mixture of two and only a lesser amount, methyl hexadecanoate or methyl palmitate, (9Z)-octadecenoic acid methyl ester, representing only $17.41 \%$ crude extract.

Table 2. Chemical composition of hexane extract of the culture of F. oxysporum SS50.

\begin{tabular}{cccccc}
\hline peak & $\begin{array}{c}\text { RT } \\
(\mathrm{min})\end{array}$ & \multicolumn{1}{c}{ Compound } & $(\%)$ & KI exp. ${ }^{\mathrm{a}}$ & KI lit. \\
\hline 1 & 9.248 & $(2 E, 4 E)$-decadienal & 0.32 & 1320 & 1319 \\
2 & 15.191 & pentadecane & 0.37 & 1500 & 1500 \\
3 & 18.770 & hexadecane & 0.62 & 1599 & 1600 \\
4 & 22.337 & heptadecane & 0.51 & 1699 & 1700 \\
5 & 25.821 & octadecane & 0.68 & 1800 & 1800 \\
6 & 27.688 & $\begin{array}{l}\text { 1,2- } \\
\text { benzenedicarboxylic }\end{array}$ & 0.62 & 1855 & $*$ \\
& & acid, bis(2- & & \\
7 & 30.004 & methylpropyl) ester & & & \\
& & methyl palmitate or & 9.73 & 1925 & 1927 \\
9 & 35.285 & (9Z,12Z)- & & 2092 & 2092 \\
& & octadecadienoic acid & & & \\
11 & 35.461 & methyl ester & & & \\
& & mZ)-octadecenoic acid & 4.70 & 2097 & $*$ \\
22 & 61.520 & dehydroergosterol & 1.94 & 3133 & $*$ \\
23 & 64.693 & clionasterol & 1.51 & 3283 & $*$ \\
24 & 67.826 & stigmast-4-en-3-one & 1.36 & 3407 & $*$ \\
\hline
\end{tabular}

${ }^{\mathrm{a}} \mathrm{KI}$ exp: Kovats indices using the experimental equation Van den Dool; ${ }^{b} \mathrm{KI}$ lit.: Kovats indices according to the literature (Adams, 1995). *Kovats index not found in the literature.

Previously reported data found that another mixture of three fatty acid methyl esters (methyl myristate, methyl palmitate and methyl stearate), isolated from the ascidian Didemnum psammatodes, also showed high cytotoxic activity and antiproliferative effects against four cell lines leukemia. The mechanism of action of these fatty acid methyl esters was found to involve inhibition of DNA synthesis and induction of both necrosis and apoptosis (Takeara et al., 2008). The major constituent of this mixture is the methyl palmitate or methyl hexadecanoate, also identified as one of the three constituents of the mixture of methyl esters present in the SS50-HxS extract. Still according to the literature, when each methyl ester blend was tested separately, the cytotoxic activity decreased, suggesting that a synergistic effect of the mixture of fatty acid methyl esters (Takeara et al., 2008).

The SS46-EaS extract exhibited high cytotoxicity against the colon cancer cells $(84.82 \%)$ and moderate cytotoxicity against central nervous system cancer cells (67.02\%) (Table 1). This extract was subjected to vacuum liquid chromatography, and subsequent purification of the resulting fractions by chromatographic techniques resulted 
in the isolation of $\mathbf{1}$. The SS46-EaL extract showed the higher cytotoxicities against the three human cancer cell lines: colon (100.0\%), melanoma (99.32\%) and central nervous system (100.0\%). The SS46-EaL extract was fractionated by column chromatography resulting in the isolation of compound 2. Analysis of the ${ }^{1} \mathrm{H}$ NMR, ${ }^{13} \mathrm{C}$ NMR, HMQC and HMBC spectra, together with HRESIMS data and comparison to literature data, led to the identification of compounds $\mathbf{1}$ and $\mathbf{2}$ as the naphthoquinone anhydrofusarubin and the cyclo-hexadepsipeptide beauvericin, respectively (Kurobane et al., 1980; Zhan et $\mathrm{al}, 2007)$. The occurrence of naphthoquinone 1 and cyclohexadepsipeptide 2 has been previously reported in the genus Fusarium (Tatum \& Baker, 1983).
1<smiles>COC1C(=O)C(O)C(=O)c2c(O)c3c(c(O)c21)COC(C)=C3</smiles>

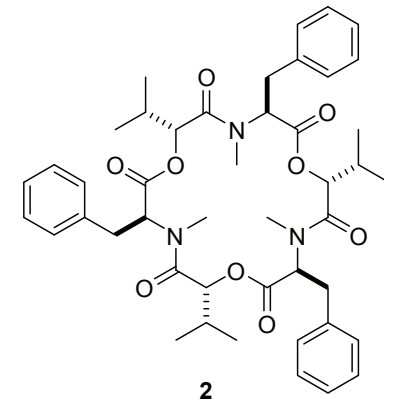

2
The cytotoxic activities of compounds $\mathbf{1}$ and $\mathbf{2}$ were evaluated in vitro against the three cancer cell lines. Anhydrofusarubin (1) and beauvericin (2) presented significant cytotoxicity against all the evaluated cancer cells, and the IC50 values ranged from 2.39 to $9.85 \mu \mathrm{g} /$ $\mathrm{mL}$ (Table 3). Anhydrofusarubin (1) was recently isolated from a marine Fusarium sp. strain and showed selective cytotoxicity against human oral carcinoma cell lines (KB cells) and breast cancer (MCF-7) (Trisuwan et al., 2010). It has been reported previously in the literature in vitro cytotoxic activity of beauvericin (2), also isolated from an endophytic $F$. oxysporum strain, in other cell lines of human cancer (Zhan et al., 2007). Compound $\mathbf{2}$ is an ionophore able to transport cations across the membranes, especially calcium, leading to the cytotoxic effects (Zhan et al, 2007; Wang \& Xu, 2012). As part of our research interest in finding antiparasitic compounds, beauvericin (2) was tested in vitro against promastigotes of Leishmania braziliensis, and showed EC50 $1.86 \mu \mathrm{M}$. Therefore, compound $\mathbf{2}$ can be considered an interesting leishmanicidal natural product for further structure diversification. Beauvericin (2) had already been reported as a bioactive compound against other cancer lines, HIV1 virus and bacterial strains (Wang \& $\mathrm{Li}, 2012$ ). We now report the activity of beauvericin against different cancer lines and, for the first time, against L. braziliensis.

This study demonstrated that strains of fungal endophytes, identified as the same species and isolated from the same plant tissue, may vary considerably in the class of secondary metabolites produced. They may also produce different compounds depending on culturing conditions. F. oxysporum SS46 produced compound 1 in solid medium, and the cyclo-hexadepsipeptide $\mathbf{2}$ in liquid medium, both compounds extracted with ethyl acetate after 21 days of fungal fermentation. These compounds have important antiproliferative properties selective for cancer cells that might explain the cytotoxicities observed for the extracts. There was no production of these compounds by $F$. oxysporum SS50, which synthesizes predominantly fatty acid methyl esters and alkanes in solid medium.

Table 3. In vitro cytotoxic activity of compounds $\mathbf{1}$ and $\mathbf{2}$, IC50.

\begin{tabular}{lccc}
\hline \multirow{2}{*}{ Compound } & \multicolumn{3}{c}{ Cell lines - IC50 $\mu \mathrm{g} / \mathrm{mL}(\mathrm{IC} 95)^{\mathrm{a}}$} \\
\cline { 2 - 4 } & HCT-8 & MDA-MB435 & SF295 \\
\hline Compound 1 & 9.85 & 6.23 & 6.32 \\
& $(7.59-12.79)$ & $(4.99-7.78)$ & $(4.38-9.11)$ \\
Compound 2 & 3.02 & 3.17 & 2.39 \\
& $(2.73-3.34)$ & $(2.56-3.93)$ & $(1.89-3.02)$ \\
Doxorubicin & 0.04 & 0.2 & 0.04 \\
(positive control) & $(0.02-0.06)$ & $(0.1-0.34)$ & $(0.01-0.005)$ \\
\hline aC95: 95\% confidence interval. & &
\end{tabular}

\section{Acknowledgments}

The authors are grateful to FAPESP, CNPq and CAPES for financial aid. This work was carried out in the INCT-INBEQMeDI (Instituto Nacional de Biotecnologia Estrutural e Química Medicinal em Doenças Infecciosas).

\section{References}

Adams RP 1995. Identification of essential oil components by gas chromatography/mass spectrometry. Illinois: Allured Publ.

Borges WS, Borges KB, Bonato PS, Said. S, Pupo MT 2009. Endophytic fungi: natural products, enzymes and biotransformation. Curr Org Chem 13: 1137-1163.

Borges WS, Mancilla G, Guimarães DO, Duran-Patron R., Colado IG, Pupo MT 2011. Azaphilones from the endophyte Chaetomium globosum. J Nat Prod 74: 1182-1187.

Dutta A, Bandyopadhyay S, Mandal C, Chatterjee M 2005. Development of a modified MTT assay for screening antimonial resistant field isolates of Indian visceral leishmaniasis. Parasitol Int 54: 119-122.

Gallo MBC, Chagas FO, Almeida MO, Macedo CC, Cavalcanti BC, Barros FWA, Moraes MO, Costa-Lotufo LV, Pessoa C, Bastos JK, Pupo MT 2009. Endophytic fungi found in association with Smallanthus sonchifolius (Asteraceae) as resourceful producers of cytotoxic bioactive natural products. J Basic Microbiol 49: 142-151. 
Gallo MBC, Cavalcanti BC, Barros FWA, Moraes, MO, CostaLotuffo LV, Pessoa CO, Bastos JK, Pupo MT 2010. Chemical constituents of Papulaspora immersa, an endophyte from Smallanthus sonchifolius (Asteraceae), and their cytotoxic activity. Chem Biodivers 7: 29412950.

Guimarães DO, Borges WS, Vieira NJ, Oliveira LF, Silva CHTP, Lopes NP, Dias LG, Duran-Patron R, Collado IG, Pupo MT 2010. Diketopiperazines produced by endophytic fungi found in association with two Asteraceae species. Phytochemistry 71: 1423-1429.

Gunatilaka AAL 2006. Natural products from plant-associated microorganisms: distribution, structural diversity, bioactivity, and implications of their occurrence. $J$ Nat Prod 69: 509-526.

Kurobane I, Vining L, Mcinnes AG, Walter JA 1980. Use of ${ }^{13} \mathrm{C}$ in biosynthetic studies. The labeling pattern in dihydrofusarubin enriched from $\left[{ }^{13} \mathrm{C}\right]$ - and $\left[{ }^{13} \mathrm{C},{ }^{2} \mathrm{H}\right]$ acetate in cultures of Fusarium solani. Can J Chem 58: 1380-1385.

Mosmann T 1983. Rapid colorimetric assay for cellular growth and survival: application to proliferation and cytotoxicity assays. J Immunol Methods 65: 55-63.

Newman DJ, Cragg GM 2012. Natural products as sources of new drugs over the 30 years from 1981 to 2010. J Nat Prod 75: 311-335.

Takeara R, Jimenez PC, Wilke DV, Moraes MO, Pessoa C, Lopes NP, Lopes JLC, Lotufo TMC, Costa-Lotufo LV 2008. Antileukemic effects of Didemnum psammatodes (Tunicata: Ascidiacea) constituents. Comp Biochem
Physiol Part A 151: 363-369.

Tatum JH, Baker RA, 1983. Naphthoquinones produced by Fusarium solani isolated from citrus. Phytochemistry 22: 543-547.

Trisuwan K, Khamthong N, Rukachaisirikul V, Phongpaichit S, Preedanon S, Sakayaroj J 2010. Anthraquinone, cyclopentanone, and naphthoquinone derivatives from the sea fan-derived fungi Fusarium spp. PSU-F14 and PSU-F135. J Nat Prod 73: 1507-1511.

Van den Dool H, Kratz PD 1963. A generalization of the retention index system including linear temperature programmed gas liquid partition chromatography. $J$ Chromatogr 11: 463-471.

Wang Q, Lijian, X 2012. Beauvericin, a bioactive compound produced by fungi: a short review. Molecules 17, 23672377.

Zhan, J, Burns AM, Liu MX, Faeth SH, Gunatilaka AAL 2007. Search for cell motility and angiogenesis inhibitors with potential anticancer activity: beauvericin and other constituents of two endophytic strains of Fusarium oxysporum. J Nat Prod 70: 227-232.

\section{*Correspondence}

\section{Mônica T. Pupo}

Departamento de Ciências Farmacêuticas, Faculdade de Ciências Farmacêuticas de Ribeirão Preto, Universidade de São Paulo, 14040-903 Ribeirão Preto-SP, Brazil mtpupo@fcfrp.usp.br 